\title{
Galarza y su amistad con intelectuales egipcios
}

\section{Galarza and his friendship with some Egyptian intellectuals}

\author{
Aḥmad `Abd al-Ḥalîm `AṬ̂iYA \\ Universidad de El Cairo \\ aorakphalsaphia@yahoo.com
}

Recibido: noviembre 2012

Aceptado: marzo 2013

\section{RESUMEN}

Vicente Galarza y Pérez Castañeda (1878-1938), conocido en Egipto como Conde de Galarza, llegó a este país en 1905 y se dedicó primero a la arqueología, y luego a la enseñanza de la filosofía en la recién fundada Universidad Egipcia, entre los años 1915 y 1921, y en la Escuela Superior del Magisterio, entre 1921 y 1931. Durante estos años trabó amistad con figuras de la vida política e intelectual egipcia y el artículo proyecta luz sobre esta relación.

Palabras clave: Vicente Galarza y Pérez Castañeda, Universidad Egipcia, Muḥammad Luṭ̂i Jumª́a, Mayy Ziyâdeh, teosofismo.

\begin{abstract}
Vicente Galarza y Pérez Castañeda (1878-1938), known in Egypt as the Count of Galarza, arrived in the country in 1905, he first engaged in archeological work and afterwards in teaching philosophy at the recently founded Egyptian University, for the years 1915-1921, and at the Higher School for Teachers Training, for the years 1921-1931. Through all these years he established friendship with personalities of the Egyptian political and intellectual life, and this article sheds light on the above mentioned relationship.

Keywords: Vicente Galarza y Pérez Castañeda, Egyptian University, Muḥammad Luṭ̂î Jumª a, Mayy Ziyâdeh, theosophy.

SUMARIO: 1. Introducción, 2. Referencias del Conde de Galarza en las cartas de Muhammad Luṭ̂î Ğum 'a (m. 1953), 3. La correspondencia con Mayy Ziyâda (1886-1941).
\end{abstract}

\footnotetext{
* Traducción de Josep Puig Montada. Departamento de Estudios Árabes, Universidad Complutense.
} 


\section{INTRODUCCIÓN}

Los escritos del profesor español Conde de Galarza reflejan la imagen del profesor que enseñó filosofía desde la primera mitad del siglo XX hasta principios del último tercio del mismo, primero en la Universidad Egipcia, entre 1915 y 1921 y luego en la Escuela Superior del Magisterio, ambas en El Cairo ${ }^{1}$. Fue uno de los profesores de la primera generación de la Universidad Egipcia, y uno de los pioneros en enseñar filosofía a nuevas generaciones y durante muchos años, haciéndolo de una manera muy distinta a como se enseñaba filosofía en el Azhar, la antigua universidad religiosa.

Los archivos de la antigua Universidad Egipcia contienen listas con muchos nombres de aquellos que estudiaron en ella, durante aquel periodo ${ }^{2}$, como ocurre con el listado detallado de los estudiantes que asistieron a las clases de Galarza el curso 1919-1920, el año de la revolución egipcia [contra la ocupación británica], y por esto es probable que el número fuera más bajo que en años anteriores. Vemos que los alumnos de Galarza en la asignatura "Filosofía general e historia de la filosofía" fueron 467, y los de "Filosofía árabe y ética" fueron $492^{3}$. Los archivos conservan los nombres de 34 estudiantes que se presentaron a los exámenes en las dos asignaturas. Los números se desglosan de la siguiente manera: 14 alumnos en 1916, 14, en 1917, 13 en 1918, 7, en 1919, 4, en 1920, 6, en 1921, egipcios y extranjeros, šuyûh (alumnos graduados del Azhar) y efendis (procedentes de las escuelas civiles) ${ }^{4}$.

${ }^{1}$ Hemos ofrecido un estudio analítico de estas obras con el título "El Conde de Galarza y los estudios de filosofía en la Universidad Egipcia" en Awrâq falsafîya (El Cairo) no 22 (2009). El artículo se tradujo al español y se publicó en los Anales del Seminario de Historia de la Filosofía 20 (2003) 285-300. Mușțafà AL-NAŠŠÂR ha publicado "El Conde de Galarza y la filosofía griega" en Awrâq falsafíya n 22 (2009), y Rağâ' AHMAD 'ALÎ, "El método crítico según Galarza en el estudio de la filosofía árabe", Awrâq falsafiyya 29 (2011). Todos estos estudios tratan de los libros y trabajos de Galarza en la Universidad Egipcia, y en la Escuela Superior de Magisterio.

N.T. Una biografía de Galarza en base a la documentación existente en los archivos de la Embajada de España en El Cairo ha sido escrita por María del Mar GARCÍA BENASACH. Es accesible en internet: http://capote.maxerco.es/histories/GALARZA\%20PEREZ\%20CASTA\%C3\%91EDA_VICENTE.pdf e impresa como "Papeles sobre la vida de Vicente Galarza Pérez-Castañeda", en Awrâq falsafíya Philosophical Papers 22 (2009) 21-27. También puede consultarse: PUIG MONTADA, Josep: "Anotación sobre Vicente Galarza y Pérez-Castañeda". Anales del Seminario de Historia de la Filosofia 21 (2005) 271-273.

${ }^{2}$ Hemos publicado los documentos de la Universidad Egipcia, y las listas de alumnos que asistían a las clases de Galarza en un apéndice a la obra de este Filosofia griega "Al-falsafa al-yûnânîya" (El Cairo: Dâr al-țaqâfa, 2008), pp. 183-189.

${ }^{3}$ Filosofía griega, en nota anterior, p. 188.

${ }^{4}$ Cito los nombres de Muhammad al-Sayyid Šâdî, el jeque Sayyid Riḍ̂ân 'Uthmân, el jeque Muhammad Mutâwi' Nasîr, el jeque Muhammad 'Aliuwâ Muștafà, el jeque Muhammad Nâṣif, el jeque Aḥmad Aḥmad 'Imâra, el jeque Muḥammad 'Abd al-'Aẓ̂m Ḥağğâb, 'Abd al-Ḥamîd al-'Ibâdî Efendî, el jeque Hamza 'Abd al-Samad, 'Abd al-'Azîz Efendi Muhammad, Husayn Fahmî al-Dağânî, 
Mencionaremos algunos nombres de aquellos que luego jugaron un papel importante tanto en la universidad como en la vida pública: el jeque Zakî Mubârak, que se doctoró en filosofía en la Universidad Egipcia, Tawfîq Ḥâmid Efendî alMar'ašalî, que fundó el movimiento cooperativista en Egipto y escribió una serie de obras al respectos, ‘Abd al-Wahhâb 'Izâm, que llegó a ser decano de la Facultad de Letras en la Universidad Egipcia, además de aquellos que estudiaron las obras de Galarza, aunque no fueron alumnos directos, por ejemplo: 'Utmân Amîn, que se apoyó en sus estudios e hizo referencia a los mismos en su obra sobre la filosofía estoica, Tawfî̀ al-Ṭawîl, en la filosofía moral, y 'Abd al-Raḥmân Badawî en la filosofía general ${ }^{6}$.

Sin embargo, aquí no nos detendremos en considerar este aspecto, el aspecto del profesor universitario, como tampoco nos detendremos en su aspecto de arqueólogo, un aspecto que el gran arqueólogo egipcio 'Abd al-Halîm Nûr al-Dîn ha destacado?, ni en su aspecto como abogado en los tribunales mixtos, unos tribunales que había en Egipto especiales para los europeos, condición que el mismo Galarza señala en el título de sus libros Diálogos de la sabiduría ${ }^{8}$; bajo este aspecto Galarza intervino en la vida egipcia del momento, y conoció al líder más importante del nuevo Egipto, Sa d Bâšâ Zag̉lûl, cabeza de la revolución egipcia de 1919.

Aquella fue una revolución que se parece en muchos aspectos a la revolución que ahora vivimos, una revolución egipcia popular que reivindica la libertad y la dignidad y que la dirigen los jóvenes y los intelectuales.

Muhammad Kamâl Ḥilmî, Tawfîq Ḥâmid al-Mar'ašalî, el jeque Ḥasan Hamza 'Abd al-Samad, el jeque Zakî 'Abd al-Salâm Mubârak, 'Alî Efendî Mazhar, el jeque Muhammad Ibrâhîm al-Ğazîrî, el jeque Muḥammad Muștafâ Abû Durra, el jeque Šihâta 'Awd Šiḥ̂ata.

${ }^{5}$ Tawfîq Hâmid al-Mar'ašalî estudió en la Universidad Privada, y hemos visto que las lecciones de Massignon de "Historia de los términos filosóficos" en la Universidad Egipcia están copiadas de su mano. Al-Mar'ašalî fue compañero de Țâhâ Ḥusayn, que siguió estas lecciones. Al-Mar'ašalî es uno de los siete graduados que obtuvieron el doctorado en la antigua Universidad Egipcia; fue profesor en la Escuela Secundaria Jedival, y el primero en introducir la enseñanza de la educación nacional en las escuelas egipcias; tiene numerosas obras de historia y sobre cooperativismo.

${ }^{6}$ 'Uthmân Amîn señala que recurre a las lecciones de Galarza en su estudio de la filosofía estoica. Son las lecciones sobre filosofía griega que hemos publicado últimamente. Así mismo hallamos huellas de la influencia de Galarza en la ética y, en particular, en la obra de Tawfî̀ AL-ṬAWÎL, Ética, su origen y desarrollo "Falsafat al-ahlâq, naš'âtu-hâ wa-tațawwuru-hâ". De ahí vendría su orientación idealista y su concentración en la ética kantiana. 'Abd al-Raḥmân Badawî, en su autobiografía, nos dice que los escritos de Galarza estaban detrás de su preocupación y sus lecturas de filosofía, antes de estudiarla en la universidad. Cf. mi estudio introductorio a Galarza, Filosofía griega, El Cairo: Dâr alTaqâfa, 2008.

7 “Abd al-Ḥalîm NÛR AL-DÎN, "Galarza y la arqueología egipcia” en La filosofía española actual, "Alfalsafa al-isbânîya al-mueâșira”, en el mencionado número 29 de Awrâq falsafìya (2011), pp. 263-274.

8 "Muhâwarât fî 1-hịikma", con este título, Galarza publicó dos libros, El Cairo: Imprenta alI'timâd, 1923-24. 
Aquí nos detendremos en la relación de Galarza con algunos intelectuales en los años veinte del siglo pasado. Hemos elegido, entre ellos, a Muhammad Luṭ̂i Ğum ‘a (1886-1953), y a Mayy Ziyâda, la famosa poetisa árabe ${ }^{9}$, y expondremos esta relación basándonos en la correspondencia que intercambiaron Galarza y aquellos dos, y que ayuda a clarificar los intereses científicos en aquel periodo.

\section{REFERENCIAS DEL CONDE DE GALARZA EN LAS CARTAS DE MUḤAMMAD LUṬFî ĞUM'A (M. 1953)}

Luṭ̂i Ğum a hace referencia en sus Memorias ${ }^{10}$ a un libro que compuso con el título Ahmad Garad o el Mahdi esperado y dice allí: "Es una colección de historias, hechos y cartas, que están relacionadas con mi amigo español el Conde de Galarza, residente en El Cairo, y quiero estudiar el tema de la ciencia espiritista... para publicar este libro completo; reuní los dichos de Ahmad Garad en 1911. El editor del libro que contiene las cartas de Luṭ̂i Ğum'a anota al margen: "No he encontrado entre los manuscritos de Luṭfi Ğum 'a el libro sobre Aḥmad Garạ al que se refiere". Es algo lamentable porque la existencia de un libro como este nos daría a conocer aspectos importantes de la personalidad del Conde de Galarza ya que solamente encontramos en las memorias de Muḥammad Luṭ̂i Ğum 'a algunas notas breves. Dicen estas:

Encontré a un amigo que me invitó a visitar a un hombre excéntrico en uno de los grandes hoteles de El Cairo que se llamaba Ahmad Garaḍ ("la intención"). Cuando llegamos, encontré a un hombre de edad indefinida envuelto en una especie de capa de color negro, cuyos bordes estaban raídos, que hablaba varias lenguas y hablaba pausadamente en árabe clásico; su nombre era Conde de Galarza, era de origen español, heredero de unas minas de plata y mercurio, de cultura musulmana, y se dedicaba al estudio de los espíritus. Para mí fue un extraño descubrimiento. Su conversación giraba en torno a la transmigración o metempsicosis, pretendiendo estar en comunicación permanente con los espíritus, los cuales lo visitaban y le mandaban mensajes a través de un aparato que había inventado y que llamaba "gharadómetro". Nada concreto resultaba de la visión, de la conversación, de los amigos ni de las reflexiones de aquel hombre. Poco después fue nombrado profesor de filosofía en la Universidad Egipcia, compuso un libro, tuvo numerosos alumnos, y se le rindió una fiesta de homenaje. Tiene una fotografía junto con Sa'd Zag̉lûl Bâsâa. Esto ocurrió después de unos incidentes que quizá expuse demasiado brevemente ${ }^{11}$.

${ }^{9}$ Cf. nuestro capítulo "La primera generación de estudiantes de la Universidad Egipcia", en El discurso filosófico en Egipto, “Al-ḥitâb al-falsafî fî Mișr”. El Cairo: Dâr Qibâ', 2001.

${ }^{10}$ ĞUM'A, Muhammad Lutfî́, Testigo de una época. Memorias de Muhammad Lutfí Ğum'a, "Šâhid al- 'așr. Muḍakkirât Muḥammad Luṭ̂î Ğum a". El Cairo: al-Hay’a al-mișrîya al- âmma li-lkitâb, 2009.

${ }_{11}$ "Te preguntan por el espíritu. Fantasmas, sueños y el Conde de Galarza", en Testigo de una época. Memorias de Muhammad Lutfi Ğum'a, pp. 381-389. 
En lo dicho por Luṭî Ğum a aparecen unos datos exactos sobre el Conde de Galarza, tales como que este fue luego profesor de filosofía en la Universidad Egipcia, que se relacionaba con el líder egipcio Sa d Zagilûl, que hay una fotografía con él, aunque no sabemos exactamente cuánto se conocían.

Vemos que tenía un alto nivel de vida, ya que se alojaba en uno de los grandes hoteles de El Cairo, ya que había heredado unas minas de plata y mercurio ${ }^{12}$. Esto explica el presupuesto que destinó a las excavaciones arqueológicas, como lo atestiguan varios estudios que publicó sobre sus excavaciones en la Revista del Museo Egipcio, "Mağallat al-Mathaf al-Misrî".

Unas rarezas que Luṭ̂i Ğum 'a no pudo explicar al principio consistían en que era un hombre excéntrico, de edad indefinida, en que llevaba una vestimenta especial; era un extraño descubrimiento. Este carácter raro se refuerza con la indicación de que Galarza se dedicaba al estudio de los espíritus, de que la conversación giraba en torno a la transmigración de las almas, de que estaba en comunicación continua con los espíritus, de que lo visitaban y le enviaban mensajes por un aparato que había inventado y que llamaba "gharadómetro" (literalmente, medidor de intención). Estas rarezas explican su interés y sus viajes a la India. También esto nos hace preguntarnos si su interés por las ruinas faraónicas, su apasionamiento por ellas, su esfuerzo en hacer excavaciones, si todo ello no estaba relacionado con su afición al espiritismo.

Si volvemos a su correspondencia con Muhammad Lutfí Ğum 'a, consistente de hecho en unas notas (tarjetas postales), encontramos dos, la primera fechada el 30 de agosto 1917, y la segunda sin fecha, y no sabemos cuál es anterior. Nos interesa la primera, pues está relacionada con sus clases: "Querido Bey, necesito urgentemente las obras de Descartes, que le pedí, para poder preparar mis lecciones en la Universidad, ruego que me las preste por un mes a través de la biblioteca". La segunda es solamente para fijar una cita: "Estaré a su entera disposición el lunes 25, a las cinco, después de mis lecciones, en la sala de profesores, ¿le va bien esta hora? Si le va mal, ¿podemos profundizar en nuestra conversación el martes a las dos, o a las cinco? Suyo sinceramente, Conde de Galarza". ${ }^{3}$

En su primera carta, Galarza se dirige a Lutfî Ğum a utilizando un tratamiento que recibía la clase más alta "Querido Bey", mientras en la segunda lo hace diciendo "Mi querido compañero". Luṭ̂i Ğum'a estudió derecho en Francia, y es autor de numerosos estudios sobre historia, derecho, literatura, y filosofía. Dominaba, pues, el francés y las dos notas están en francés. Ğum a escribió importantes obras de filosofía, cosa que Galarza sabía. Le pedía los textos de

${ }^{12}$ N.T. La afirmación es fantasiosa, pues su riqueza provenía de los padres, sobre todo de su padre, propietario de negocios y tierras en Cuba. Ver el expediente personal del padre, Vicente Galarza y Zuloaga, senador por varias provincias de Cuba, en el archivo del Senado, signatura: HIS-0173-04.

${ }^{13}$ N.T. Documentación en poder del autor. 
Descartes en francés, para preparar las lecciones del curso próximo, pues la nota lleva fecha de 30 de agosto 1917, un mes antes, y lo hacía con urgencia, tal como dice "Necesito urgentemente las obras de Descartes".

\section{LA CORRESPONDENCIA CON MAYY ZIYÂDA (1886-1941)}

Entre el profesor español y la literata árabe se cruzaron buen número de cartas a lo largo de diez años. La primera tiene fecha de 6 de enero 1918, y la última, 8 de octubre 1928. Sin embargo, Mayy conocía a Galarza antes de aquella fecha pues ella pronunció un discurso en la fiesta de homenaje que le dieron sus alumnos el 13 de abril 1917, discurso que se publicó en la revista Al-muqtațaf, "Selección" en el número de agosto $1919^{14}$, páginas 132-133, y se reimprimió en el libro Mayy. Palabras e indicaciones, "Mayy. Kalimât wa-išarât".

No nos detendremos en el discurso ahora ${ }^{15}$, solamente aludiremos a dos observaciones que nos parece que son obra del redactor de Al-muqtataf y que revelan la presencia de Galarza en la vida cultural egipcia. La primera es que la celebración tuvo lugar en el jardín del hotel Shepheard's bajo la presidencia del emir Haydar Fâdil y con la presencia de sabios y de personalidades nacionales y extranjeras. Habló en francés el conde Prozor, representante ruso en la Caja de la Deuda Pública, fundador de la Universidad del Pueblo y su presidente honorario ${ }^{16}$. Esta es la primera observación y está relacionada con las personalidades que tomaron parte en la celebración; son personalidades que tenían puestos políticos, como el príncipe egipcio, o el representante ruso en la Caja de la Deuda Pública ${ }^{17}$, y así mismo asistieron el legado de España don Cristóbal Fernández-Vallín, y el cónsul Sr. Carreras.

La segunda observación la hace el redactor, diciendo en una nota: "Merece la pena señalar algo que no tiene relación directa con nuestro objeto (el discurso de Mayy) pero que tiene mucha relación con el Conde de Galarza, pues este nombre ruso es famoso entre los espiritistas. Los seguidores de la teosofía creen que el

${ }^{14}$ N.T. Exactamente, en ZIYÂDA, Mayy, "El renacimiento próximo", "Al-ba't al- ‘atîd", publicado en Al-muqtataf, agosto 1919, el cual ocupa pp. 129-134.

${ }^{15}$ N.T. Traducción de un fragmento en "El Conde de Galarza y el método crítico en la enseñanza de la filosofía", en Anales del Seminario de Historia de la Filosofia 20 (2003), p. 299.

${ }^{16}$ ZIYÂDA, M., "Al-ba't al-'atîd", Al-muqtațaf, p. 129. También publicamos el texto como apéndice a la Filosofía griega, de Galarza, (El Cairo: Dâr al-țaqâfa al- 'arabîya, 2009), p. 191.

${ }^{17}$ N.T. La Caisse de la dette, Sundûq al-Dayn, fue creada por Francia e Inglaterra en 1876 para cobrar la deuda contraída por el khedive Ismail. Sus funciones fueron en aumento controlando el presupuesto del país. La deuda fue liquidada en 1912, pero el organismo subsistió hasta 1940 y esto explica que en 1917 hubiera todavía representantes de la misma. Una versión colonial justificando la Caja puede verse en COLVIN, Auckland (Sir), The Making of Modern Egypt, Londres: Seeley, 1906. Colvin fue nombrado en 1879 Comisario de la Deuda por parte inglesa. 
conde Prozor destacó por sus dotes esotéricas, hasta el punto de ver en él la figura del cuerpo astral o etéreo, y los colores de las pasiones se manifestaban en él".

El redactor añade: "El escritor teosofista C.W. Leadbeater ha descrito estos fenómenos con unos colores precisos en uno de sus famosos libros, diciendo que los dibuja siguiendo las indicaciones y la visión de Maurice Prozor ${ }^{18}$. Es una alegoría única por causa de su extraña especie". ${ }^{19}$ Lo que dice el redactor de Al-muqtataf coincide con lo que cuenta Muhammad Luṭ̂i Ğum a y explica la presencia del conde Prozor en el homenaje, probablemente por este interés común en las ciencias espiritistas, además de su peso en la vida pública egipcia.

Prestaremos atención a cuatro cartas que el Conde de Galarza escribió a Mayy. Dos empiezan con "querida señorita Isis" y dos, con "querida señorita Mayy". Isis es el nombre de la diosa más alta en la mitología faraónica, conocida en la leyenda de Isis y Osiris. El nombre tiene su significado, tanto si Mayy era así conocida o si Galarza así la llamaba. Terminan estas cartas diciendo: "Quedo tu hermano en la filosofía", "Hasta la vista, mi hermana en la filosofia", "De tu hermano en la sabiduría", "Te presento mi más alto respeto fraternal, de un jeque de la filosofía". Desde el comienzo hasta el final se nos manifiesta una profunda amistad, tanto por dirigirse a ella con la palabra "Querida", como por utilizar el nombre propio, como porque esta amistad gira en torno a la fraternidad filosófica: tu hermano, mi hermana, fraternal. Tres cartas son para agradecer a Mayy revistas o libros de ella; las cuatro cartas están escritas en francés. La fecha de cada una nos aclara el interés de Galarza en este periodo de la siguiente manera:

En la primera carta, le da las gracias a Mayy por las revistas que ella le envió y que contienen unos ensayos de Mayy sobre el aprendizaje por esta de la lengua rusa, un aprendizaje al que Galarza dedicó dos años. Galarza afirma que olvidó el ruso porque no tenía ocasión de hablar en dicha lengua. Galarza escribió esta carta el 6 de enero 1918, un año después de la revolución bolchevique, y da a entender que no sentía inclinación por el ruso, aunque no lo diga abiertamente, pues dice "no considero que en la literatura rusa haya algo que satisfaga el esfuerzo que haces por aprenderla".

Nos interesan sus palabras sobre sus proyectos científicos, son sus palabras "Mi libro sobre filosofía árabe por el que me preguntaste sigue en el mundo de lo ausente, como dicen los filósofos, y es posible que se materialice en el mundo de la palabra dentro de unos años". Sus palabras merecen un comentario porque sabemos que publicó dos libros conteniendo uno sus lecciones de filosofía general e historia de la filosofía y otro de filosofía árabe y moral el curso 1918-19, y el curso 1919-20,

${ }^{18}$ N.T. Ver la nota introductoria a Man Visible and Invisible. Examples of Different Types of Men as Seen by Means of Trained Clairvoyance, Nueva York, 1903, donde Leadbeater le agradece a Prozor la colaboración. Disponible en la red en www.blavatskyarchives.com.

${ }^{19}$ M. ZIYÂDA, en "Al-ba't al- 'atîd”, Al-muqtațaf, p. 129, nota 1; apéndice a Filosofía griega, p. 190. 
y en ambos libros trata de filosofía árabe. Por esto debemos preguntarnos si el libro de historia de la filosofía árabe, al que se refiere en la carta, es distinto de lo que publicó, ¿quería Galarza quizá hacer una obra de historia distinta de sus lecciones?

Avancemos unos párrafos de la segunda carta que escribió el 30 de junio 1920. Como en la primera se dirige a Mayy "Querida señorita Isis" y le da las gracias por enviarle su libro acerca de La que busca en el desierto, "Bâhịtat al-Bâdiya"20 , alaba la forma del libro y le promete darle su opinión después de leerlo: "Cuando termine de disfrutarlo, te diré si habré encontrado en él aquella fragancia familiar que invade a los amigos de los principios siguiendo el estandarte de Isis porque la personalidad de la madre se refleja en ella".

El lector advertirá que la expresión "aquella fragancia familiar que invade a los amigos de los principios siguiendo el estandarte de Isis" tiene un perfume platónico, como si estuviéramos en una congregación religiosa de carácter espiritualista como los pitagóricos, algo que confirma el párrafo siguiente que dice:

"En estos principios excelsos se inspiran los mensajes de los enviados de los que me hablaste, pero los momentos que celebran la existencia de una inspiración son raros, y raras veces se permite a los pueblos celebrar los nombres de aquellos con palabras nuevas. A pesar de ello, y pase lo que pase con nuestros mensajes, los pensamientos eternos tienen fuerza e influencia antes que aparezcan los mensajeros, y se emocionan los muertos que divulgaron estos principios y creyeron en ellos".

En una segunda carta, fechada el 23 de febrero 1924, se dirige a ella "Querida señorita Mayy". Con alegría ha recibido los pensamientos que los dos últimos libros de ella contienen. Habla de que su bello lenguaje ayudará a elevar el nivel espiritual de los pueblos de lengua árabe y a despegarse de lo material. Le expresa su esperanza de que en verano se publique su libro, Lecciones sobre sabiduría, "Muhâụarât fî 1-hikma", ${ }^{21}$ que ha preparado para sus alumnos. De hecho, estas lecciones se publicaron como dos libros, como hemos dicho antes, en El Cairo: Imprenta al-I'timâd, 1923-24.

La labor de Galarza no se limitó a dar clases. A través de su correspondencia así como de las personalidades que participaron en su homenaje se ve que su presencia era considerable en la vida cultural egipcia. No era un profesor aislado entre las paredes de las aulas. Aunque no era una personalidad que ejerciera un impacto cultural generalizado, sin embargo seguía una línea platónica y alegórica en sus Diálogos sobre la sabiduría tal como se manifiesta en sus palabras a Mayy, en la

${ }^{20}$ N.T. "La que busca en el desierto", alias de Malak Hifnî Nâșif (1886- 1918), una pionera del feminismo en Egipto. La obra apareció en 1920 (190 pp.) sin indicación de lugar, y fue reeditada en Beirut: Mu'assasat Nawfal, 1975.

${ }^{21}$ N.T. El autor del artículo parece haberse confundido y se refiere a los Diálogos sobre la sabiduría, que comprende dos partes. 
segunda carta, cuando habla de "aquella fragancia familiar que invade a los amigos de los principios siguiendo el estandarte de Isis".

La cuarta carta de Galarza a la querida señorita Mayy nos remite a dos aspectos. El primero son sus ocupaciones prácticas y teóricas, y sus pensamientos para viajar y abandonar Egipto, ¿acaso sus muchas ocupaciones no le dejaban tiempo para dedicarse a la ciencia espiritista? Puede que la carta lo insinúe.

Las cartas de Galarza a Mayy que conocemos contienen respuestas al libro o a los artículos que ella le enviaba. Así mismo la cuarta carta expresa su agradecimiento a Mayy por su amable preocupación por él. Galarza le da noticias suyas: hace poco el Ministerio ${ }^{22}$ le ha ofrecido un contrato de profesor y encargado de la biblioteca en la Escuela Superior de Magisterio. Añade que está dando los últimos retoques a sus obras $\mathrm{y}$, con evidente emoción, que va a continuar escribiendo para seguir en Egipto, es decir, que es una oferta del ministerio. En el contexto que tenemos delante, esto tiene su importancia, pues se le pide que continúe como profesor y encargado de la biblioteca y que complete tres libros: Platón, Espinoza y Locke, y que traduzca una obra maestra que elija. El hecho de que el ministerio lo eligiera para esta misión nos confirma sus cualificaciones científicas, que el ministerio aprovechó. No son todos los encargos requeridos pues acto seguido añade "el director quiere que clasifique 60.000 volúmenes de la biblioteca, una orden dada últimamente al Ministerio".

Nos parece, como le pareció a Galarza, que las exigencias eran excesivas. Es natural que trabajara como profesor y que se encargara de supervisar la biblioteca, y que escribiera, tradujera y ordenara, pero esto requiere un tiempo y esfuerzo que él no podía dedicar. Por esto pensaba si irse de Egipto, pero "a pesar de esto, probablemente me quedaré en Egipto", es decir, no estaba decidido.

Reanudó su trabajo y alcanzó un dominio profundo de la lengua árabe para terminar sus originales. En general, en sus originales mantiene los fundamentos de los tres libros suyos que hemos mencionado en la introducción a este artículo. Su labor científica continuó con independencia de aceptar la oferta del Ministerio, de viajar o de quedarse en Egipto.

Lamentamos no haber localizado estos trabajos pertenecientes a su última etapa, como tampoco hemos localizado el libro de Luṭ̂i Ğum`a, pues perdemos detalles numerosos e importantes sobre la vida de Galarza, pero no tenemos esperanza de encontrarlo, o casi ninguna, si es que llegó a publicarse. Así podríamos explicar los esfuerzos de un profesor que destacaba en una nación que apreciaba la ciencia y los sabios, tal como lo refleja la fiesta que se dio en su honor o el interés del Ministerio en confiarle una misión científica tan importante en aquel momento tan significativo de la historia de Egipto.

\footnotetext{
${ }^{22}$ N.T.: debe de ser el Ministerio de Instrucción, Wizârat al-Ma ârif.
} 